\title{
Inhibitory motor innervation of the gall bladder musculature by intrinsic neurones containing nitric oxide in the Australian Brush-tailed possum (Trichosurus vulpecula)
}

\author{
A C B Meedeniya, B O Al-Jiffry, H Konomi, A C Schloithe, J Toouli, G T P Saccone
}

\begin{abstract}
Background-Gall bladder functions are modulated by neurones intrinsic to the organ. Data are available on the neurochemical composition of intrinsic and extrinsic nerves innervating the gall bladder but are lacking on specific functional classes of gall bladder neurones.

Aims-To characterise the intrinsic motor neurones of the gall bladder and identify their roles using pharmacological techniques.

Methods-Retrograde tracing from the possum gall bladder muscle in vitro allowed identification of intrinsic motor neurones. Subsequently, their content of choline acetyltransferase and nitric oxide synthase, markers of acetylcholine and nitric oxide containing neurones, was established using immunohistochemical techniques. Organ bath pharmacology was used to evaluate neurotransmission by acetylcholine and nitric oxide in gall bladder muscle strips.
\end{abstract}

Results-Innervation of the gall bladder musculature by neurones of both the muscular and serosal plexuses was demonstrated. A large proportion (62\%) of these motor neurones were immunoreactive for nitric oxide synthase. All gall bladder neurones showed immunoreactivity for choline acetyltransferase. Organ bath pharmacology confirmed the neuroanatomical data, showing acetylcholine and nitric oxide mediating neurotransmission to the gall bladder musculature.

Conclusions-Neurones containing acetylcholine and nitric oxide, located within the muscular and serosal plexuses, provide excitatory and inhibitory motor innervation of the gall bladder, respectively. The large inhibitory innervation suggests active relaxation of the gall bladder during filling, mediated by intrinsic nerves. (Gut 2001;49:692-698)

Keywords: excitatory/inhibitory neurotransmission; gall bladder; motility; nitric oxide; acetylcholine; possum

The motor functions of the gastrointestinal tract are primarily regulated by the enteric nervous system. The technique of retrograde tracing in vitro combined with immunohistochemistry has defined the distribution and neurochemical composition of motor neurones within the intestine and stomach of several mammalian species. ${ }^{1-5}$ This, combined with many physiological and pharmacological studies, has allowed the characterisation of inhibitory and excitatory motor innervation within some regions of the gastrointestinal tract and has thus elucidated the neural mechanisms underlying gastrointestinal motility. The nervous system of the extrahepatic biliary tree, including the gall bladder, is confluent with the enteric nervous system and thereby it shares several of its properties. ${ }^{67}$ However, as the structure and function of the gall bladder is specialised, its anatomy and innervation differ from those of the gastrointestinal tract. ${ }^{8}$

Extensive innervation composed of both extrinsic and intrinsic neural elements is present within the mucosa, muscle, and surrounding the vasculature of the gall bladder. ${ }^{9}$ In mammals, including humans, intrinsic neurones of the gall bladder form three ganglionated plexuses: subepithelial, muscular, and serosal plexuses. ${ }^{10}$ The neurochemical content of gall bladder neurones, including acetylcholine (ACh) and nitric oxide (NO), has been described in several species. ${ }^{9-11}$ These intrinsic gall bladder neurones are proposed to regulate most gall bladder functions, including motility ${ }^{8}$ and epithelial functions. ${ }^{12}$ However, the specific functional classes of neurones within the gall bladder remain to be characterised.

Pharmacological data exist for NO mediated relaxation of the gall bladder musculature. ${ }^{13} 14$ Studies in vivo have also shown involvement of NO in gall bladder relaxation. ${ }^{15}$ Similarly, contraction of the gall bladder involves a cholinergic mechanism. ${ }^{16}$ Electron microscopy has shown the presence of nerve varicosities containing clear and large dense cored vesicles in close apposition to the gall bladder muscle. ${ }^{14}$ However, the neurochemicals present within these nerves were not investigated. Other studies have demonstrated the presence of both nitric oxide synthase (NOS) and ACh in nerve fibres close to the gall bladder musculature. ${ }^{9} 10$ However, the source of this innervation is unclear and there are no neuroanatomical data to show intrinsic neurones in the motor innervation of the gall bladder.

Abbreviations used in this paper: $\mathrm{ACh}$, acetylcholine; CCK-8, cholecystokinin octapeptide; ChAT, choline acetyltransferase; DiI,

1'-didodecyl-3,3,3'3'-tetra-methyl-indocarbocyanine perchlorate; EFS, electrical field stimulation;

L-NAME, $N$ omega-nitro-L-arginine methyl ester; NANC, non-adrenergic non-cholinergic; NO, nitric oxide; NOS, nitric oxide synthase; TTX, tetrodotoxin; VIP, vasoactive intestinal polypeptide. 
This study uses retrograde tracing in organotypic culture and immunohistochemistry to identify neurones innervating the gall bladder muscle and their neurochemical content in the Australian Brush-tailed possum. In vitro pharmacological studies using gall bladder muscle strips were performed to add functional data in support of the neuroanatomical findings.

\section{Material and methods}

The methods of retrograde tracing in organ culture combined with immunohistochemistry have been described previously ${ }^{17}$ and are outlined below. Ethics approval for these studies was granted by the Flinders University Animal Welfare Committee.

\section{TISSUE PREPARATIONS}

Twelve Australian Brush-tailed possums (Trichosurus vulpecula) $(1.2-2.0 \mathrm{~kg})$ were fasted for at least 18 hours and anaesthetised with an intramuscular injection of ketamine hydrochloride $20 \mathrm{mg} / \mathrm{kg}$ (Ketalar; Parke-Davis, NSW, Australia) and xylazine $5 \mathrm{mg} / \mathrm{kg}$ (Rompun, Bayer, NSW, Australia). The gall bladders were harvested under sterile conditions and placed in sterile Krebs solution (composition ( $\mathrm{mmol} / \mathrm{l}$ ): $\mathrm{NaCl} 117 ; \mathrm{KCl} 5 ; \mathrm{MgSO}_{4} 1.2 ; \mathrm{NaHCO}_{3} 25 ;$ $\mathrm{NaH}_{2} \mathrm{PO}_{4}$ 1.2; $\mathrm{CaCl}_{2}$ 2.5; glucose 10; bubbled with $95 \% \quad \mathrm{O}_{2} / 5 \% \mathrm{CO}_{2}$, buffered to $\mathrm{pH} 7.4$ ) containing $1 \mu \mathrm{mol} / 1$ nicardipine (Sigma Chemical Co., St Louis, Missouri, USA) and dissected open from the cystic duct to the apex, along the peritoneal aspect, and rinsed in sterile Krebs solution. For retrograde tracing from the muscle, the preparations were pinned serosal surface uppermost on a Sylgard lined petri dish (Dow Corning, Midland, Michigan, USA). Using blunt dissection, a small window $(1 \times 0.5 \mathrm{~mm})$ was made in the serosa extending through the connective tissue to the surface of the muscle layer.

ORGAN CULTURE, RETROGRADE TRACING, AND IMMUNOHISTOCHEMISTRY

The fluorescent neuronal tracer 1, 1'-didodecyl3,3,3'3'-tetra-methyl-indocarbocyanine perchlorate (DiI) (Molecular Probes, Eugene, Oregon, USA), coated on a $200 \mu \mathrm{m}$ glass bead, was focally applied to the muscle surface. The bead was removed after 24 hours of culture to prevent penetration of the tracer into underlying structures. The preparations were cultured for four days in culture medium (DME F12 (Sigma), 10\% fetal bovine serum, $1.2 \mathrm{~g} / 1$ $\mathrm{NaHCO}_{3}, 1.8 \mathrm{mmol} / 1 \mathrm{CaCl}_{2}, 2.5 \mu \mathrm{g} / \mathrm{ml}$ amphotericin, $100 \mathrm{IU} / \mathrm{ml}$ penicillin, $20 \mu \mathrm{g} / \mathrm{ml}$ gentamycin, $100 \mu \mathrm{g} / \mathrm{ml}$ streptomycin, buffered to $\mathrm{pH}$ 7.2) after which the preparations were fixed overnight in modified Zamboni's fixative $(2 \%$ formaldehyde and $15 \%$ picric acid in $0.1 \mathrm{~mol} / 1$ phosphate buffer, $\mathrm{pH}$ 7.0).

Five preparations were washed in phosphate buffered saline $(0.15 \mathrm{~mol} / 1 \mathrm{NaCl}$ in $0.01 \mathrm{~mol} / 1$ sodium phosphate, $\mathrm{pH}$ 7.2) and dissected to separate the serosal plexus from the muscle layer. The preparations were then permeabilised with glycerol for two hours to facilitate antibody penetration and incubated with the primary monoclonal antibody, mouse anti-NOS (1:1000; Transduction Laboratories, Lexington,
Kentucky, USA) for 24 hours. The primary antibody was visualised by incubating the preparations for two hours with the secondary antiserum, donkey antimouse conjugated fluorescein isothiocyanate (Jackson Immunoreasearch, Pennsylvania, USA). The preparations were mounted in bicarbonate buffered glycerol and analysed.

Three gall bladders were fixed immediately on removal from the animals and processed for visualising the marker of $\mathrm{ACh}$ synthesis, namely choline acetyltransferase (ChAT), using the antiserum goat anti-ChAT (1:200; Chemicon, Temecula, California, USA). The general neuronal marker rabbit anti-PGP 9.5 antiserum (1:400; Ultraclone, Wellow, UK) was used to identify all nerve cell bodies and fibres. The secondary antisera, donkey antigoat conjugated indodicarbocyanin and donkey antirabbit conjugated indocarbocyanin (Jackson Immunoreasearch) were used to identify the primary antisera. Colocalisation of immunoreactivities for ChAT and NOS were tested. Control experiments omitting primary antisera abolished visible labelling with the appropriate secondary antibody combinations. These antisera have been used previously. ${ }^{5}$

\section{DATA ACQUISITION AND ANALYSIS}

DiI fluorescence together with fluorescence from the neurochemical markers were visualised using an Olympus AX70 microscope fitted with epifluorescence and a video camera (SSC M370CE; Sony, Tokyo, Japan) connected to a Macintosh Quadra computer (Apple, Cupertino, California, USA). The positions of the neurones and their immunoreactivities to the neurochemical markers, relative to the DiI application site, were plotted using a high resolution computerised mapping system linked to the microscope stage. ${ }^{1}$ Immunoreactivities for ChAT and/or NOS were defined as positive when the immunoreactive cytoplasm was clearly distinguishable from the immunonegative nucleus and background. The graphics software NIH image (version 1.61, National Institute of Health) was used for plotting cell distributions and for acquiring images. Accumulation of the retrograde tracer allows assessment of neuronal morphology. ${ }^{17}$

Cell distribution data were processed on Microsoft Excel version 5.0 (Microsoft, Washington, DC, USA) and plotted on Igor Pro (WaveMetrics Inc, Eugene, Oregon, USA). The DiI application site is used as the origin for the $\mathrm{X}$ and $\mathrm{Y}$ coordinates. Data are presented as mean (SEM). The digitised images were not manipulated apart from cropping, sizing, and adjustment of contrast and brightness. The images were printed on a Kodak XLS-8600 PS dye sublimation printer.

PHARMACOLOGICAL INVESTIGATIONS OF NEUROTRANSMISSION BY NO AND ACh IN THE GALL BLADDER

Five Australian Brush-tailed possums (1.2-2.0 $\mathrm{kg}$ ) were anaesthetised as described previously, the gall bladders removed, and placed in modified Krebs solution (mmol/1: $\mathrm{Na}^{+}$151.0; $\mathrm{K}^{+} 4.7 ; \mathrm{Ca}^{2+} 2.8 ; \mathrm{Mg}^{2+} 0.6 ; \mathrm{Cl}^{-} 143.7 ; \mathrm{H}_{2} \mathrm{PO}_{4}{ }^{-}$ 

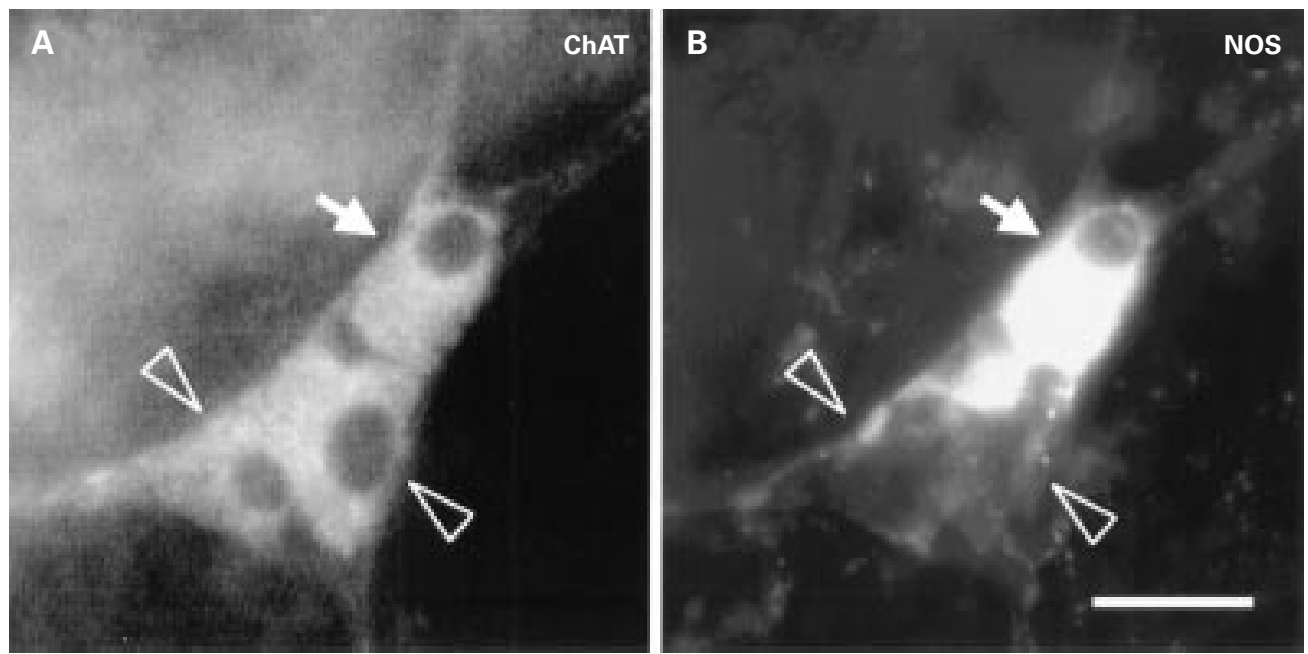

Figure 1 Photomicrographs of a ganglion of the muscular plexus in the possum gall bladder. All three neurones show choline acetyltransferase (ChAT) immunoreactivity (A). A neurone from the same ganglion shows nitric oxide synthase (NOS) immunoreactivity (arrow) while the others are immunonegative for NOS (arrowheads) (B). Bar, $20 \mu \mathrm{m}$.

$1.3 ; \mathrm{HCO}_{3}^{-} 16.3 ; \mathrm{SO}_{4}^{2-} 0.6 ;$ glucose 7.7 ; bubbled with $95 \% \mathrm{O}_{2} / 5 \% \mathrm{CO}_{2}$, buffered to $\mathrm{pH}$ 7.4). The gall bladders were opened from the cystic duct to the apex, along the hepatic aspect, and dissected to provide full thickness muscle strips ( $5 \mathrm{~mm}$ wide $\times 3 \mathrm{~cm}$ long). The strips, placed in $7 \mathrm{ml}$ organ baths containing warmed $\left(37^{\circ} \mathrm{C}\right)$ oxygenated (bubbled with 95\% $\mathrm{O}_{2} / 5 \% \mathrm{CO}_{2}$ ) modified Krebs solution and indomethacin (3 $\mu \mathrm{mol} / \mathrm{l}$; Sigma), were mounted through platinum wire ring electrodes and connected to isometric transducers (load 5-6 mN) to measure mechanical activity. ${ }^{18}$ After equilibration (one hour), all preparations were precontracted to approximately $50 \%$ of maximal with cholecystokinin octapeptide (CCK-8 $0.1 \mu \mathrm{mol} / 1$; Sigma) ${ }^{18}$ and allowed to reach an elevated stable tone (2-5 minutes). Under all conditions, electrical field stimulation (EFS) generated by a Grass S88 stimulator (Grass Instruments Co., Quincy, Massachusetts, USA) comprised stimulus trains of: five seconds duration; $10 \mathrm{~Hz} ; 0.1 \mathrm{~ms}$ pulse width; $70 \mathrm{~V}$; and 120 second intervals. This protocol, established from preliminary experiments, consistently produced a response.

The mechanical response, namely changes in tone of the preparations to EFS under four sequential pharmacological conditions, were established where mean activity during a 30 second period immediately before the onset of EFS was considered the basal level of activity. Maximal or minimal activity for a period of 30 seconds after EFS was considered evoked activity. The four treatments tested were: (1) control, (2) guanethidine (10 $\mu \mathrm{mol} / \mathrm{l}$; Sigma) and atropine (3 $\mu \mathrm{mol} / 1$; Sigma) (nonadrenergic non-cholinergic (NANC) conditions); (3) NANC conditions and $N$ omeganitro-L-arginine methyl ester (L-NAME 0.4 $\mathrm{mmol} / \mathrm{l}$; Sigma); (4) NANC conditions, L-NAME $(0.4 \mathrm{mmol} / \mathrm{l})$, and L-arginine $(0.4$ $\mathrm{mmol} / \mathrm{l}$; Sigma). Net evoked activity was calculated using basal activity (evoked minus basal activity). Tetrodotoxin (TTX $1 \mu \mathrm{mol} / 1$; Sigma) was added to the baths and EFS (as above) was applied to verify that the evoked responses were neurally mediated. Data were recorded using a
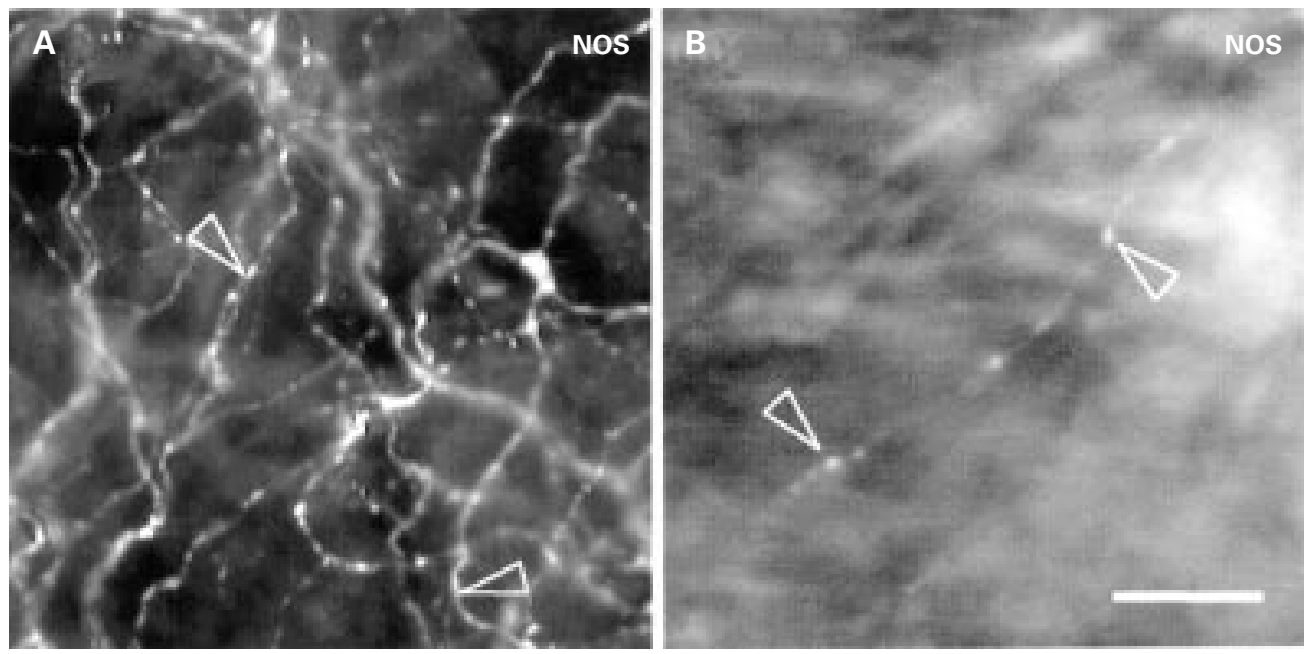

Figure 2 Photomicrograph of nitric oxide synthase (NOS) immunoreactive nerve fibres within the possum gall bladder. NOS immunoreactive nerve fibres (arrowheads) were present within the non-ganglionated subepithelial plexus $(A)$ and the muscle (B) of the gall bladder. Bar, $20 \mu \mathrm{m}$. 

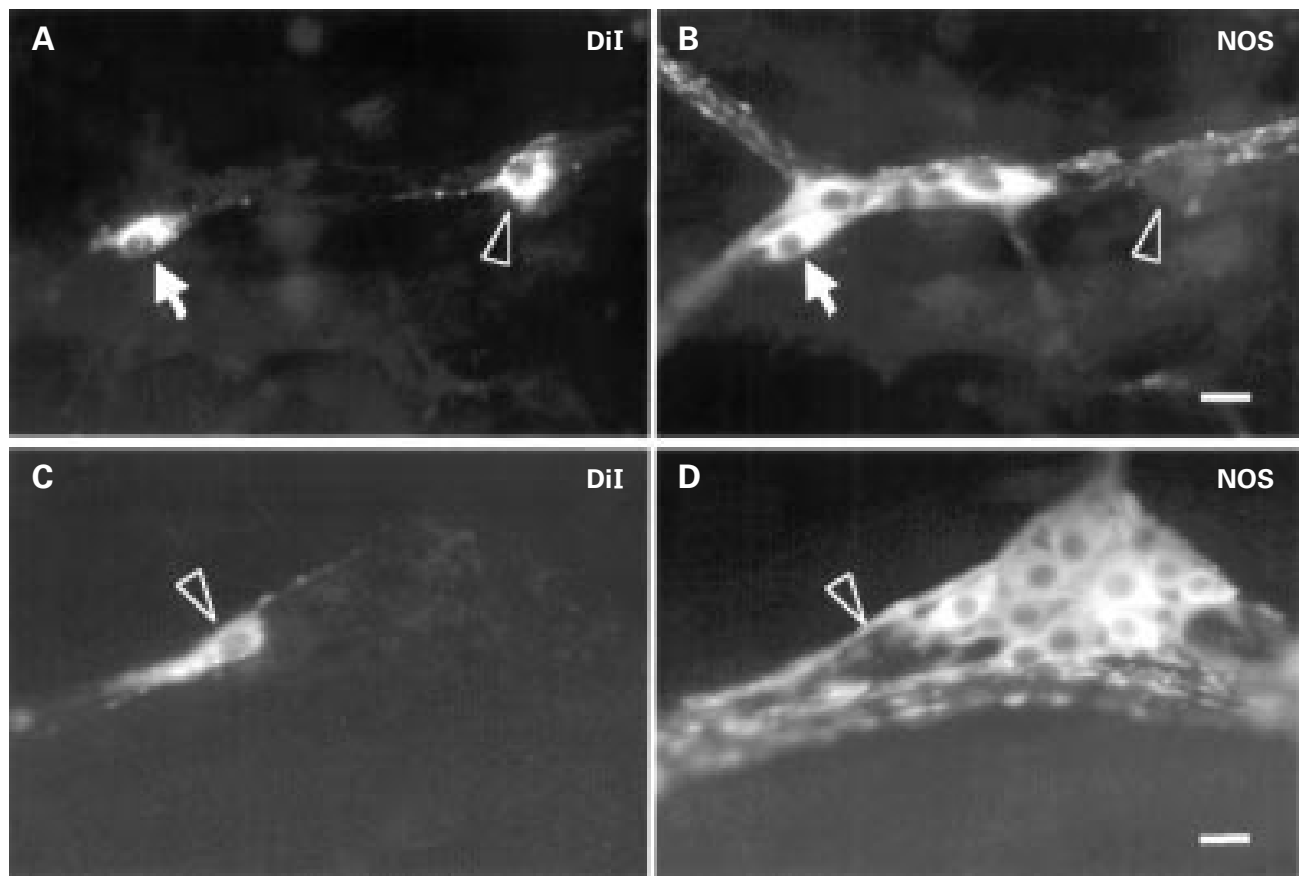

Figure 3 Retrogradely labelled neurones were found within the muscular $(A)$ and serosal plexuses $(C)$ on

1'-didodecyl-3,3,3'3'-tetra-methyl-indocarbocyanine perchlorate (DiI) application to the gall bladder muscle. Some DiI labelled cells showed immunoreactivity for nitric oxide synthase (NOS) (arrows) while others were immunonegative (arrowhead) (B, D). Bar, $20 \mu \mathrm{m}$.

MacLab recording system (ADInstruments, NSW, Australia) on a Macintosh Power PC computer running Chart 3.6/S. Data are presented as mean (SEM) with analysis of variance for testing of significance, where a $\mathrm{p}$ value $<0.05$ was considered significant.

\section{Results}

ChAT AND NOS IMMUNOREACTIVITY WITHIN THE GALL BLADDER

ChAT immunoreactivity was present in nerve fibres throughout all layers of the gall bladder, with a degree of variation in the intensity of

A Scatterplots
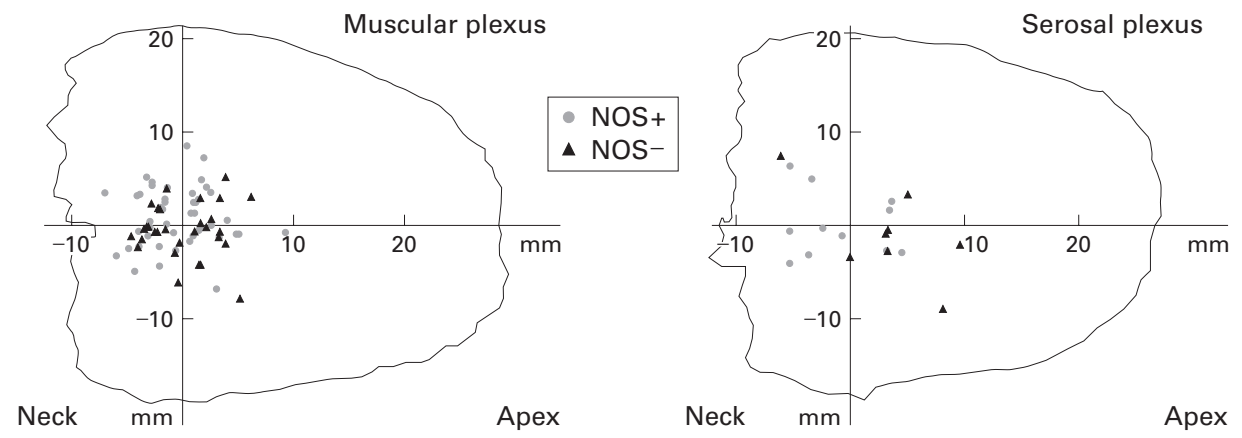

B Cumulative data

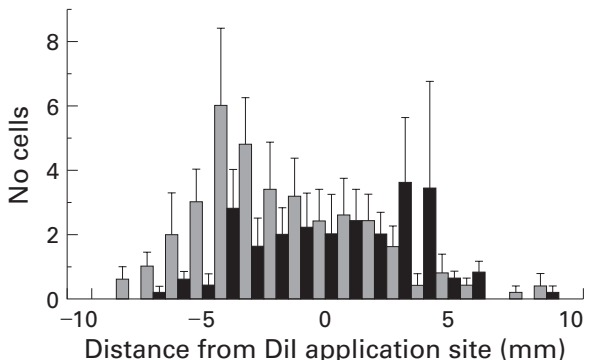

Neck

Apex

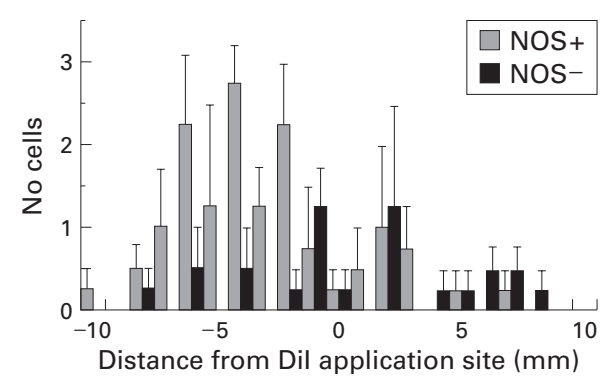

Figure 4 (A) Scatterplots of neurones retrogradely labelled on 1'-didodecyl-3,3,3'3'-tetra-methyl-indocarbocyanine perchlorate (DiI) application to the gall bladder muscle in a representative preparation. The DiI labelled neurones were primarily located close to the application site (all within $10 \mathrm{~mm}$ ). (B) Cumulative data of all DiI traced neurones from five preparations showed that nitric oxide synthase (NOS) immunoreactive neurones within both the muscular and serosal plexus were polarised in their distribution along the longitudinal axis of the gall bladder, projecting predominantly from the neck towards the apex, but NOS immunonegative cells did not show a polarised distribution. 


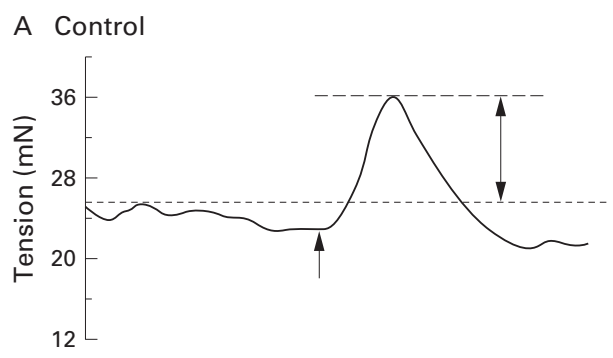

C NANC post L-NAME
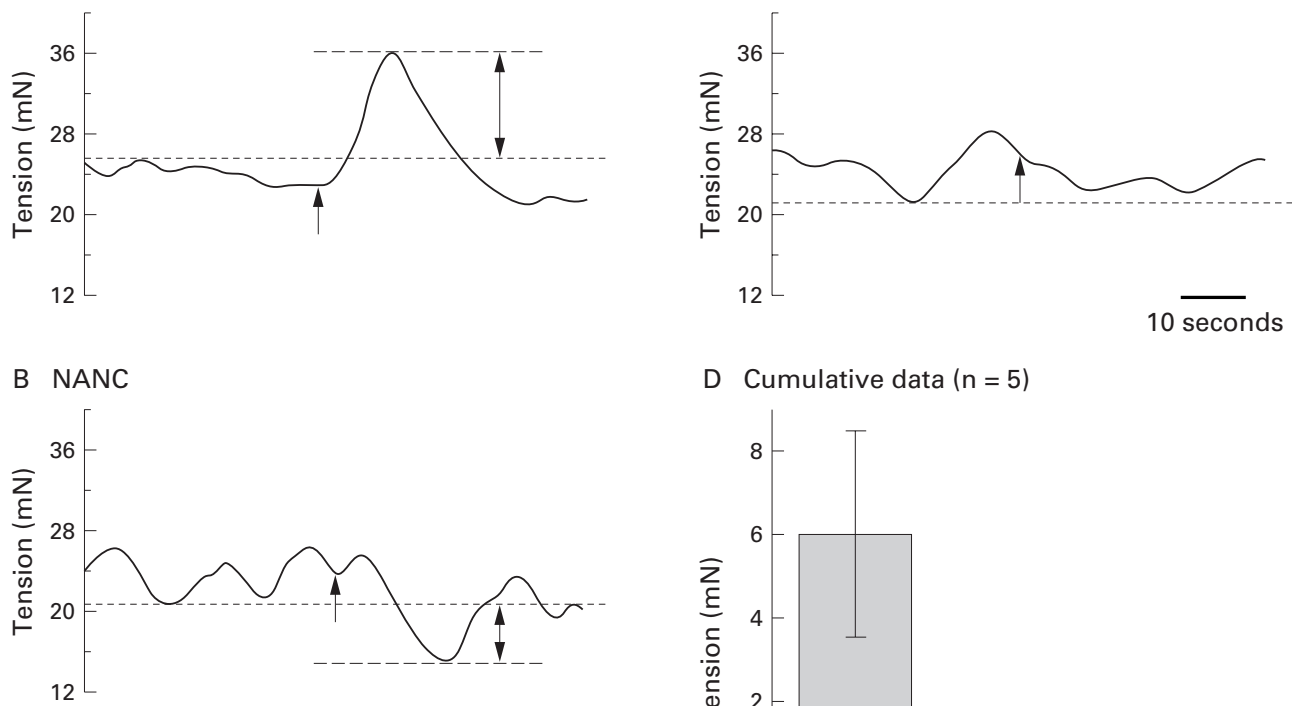

D Cumulative data $(\mathrm{n}=5)$

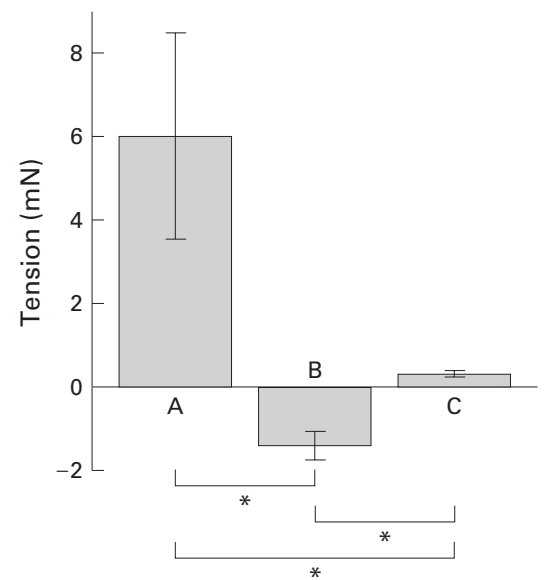

Figure 5 Representative traces and cumulative data of gall bladder muscle strip pharmacology. Electrical field stimulation EFS (arrows) produced consistent gall bladder contraction under control conditions $(A)$. Under non-adrenergic non-cholinergic (NANC) conditions, EFS produced relaxation (B). This response was abolished by $N$ omega-nitro-L-arginine methyl ester (L-NAME) (C). Cumulative data (D) are expressed as mean (SEM). All responses differed significantly $\left({ }^{\star} p<0.05\right)$ from each other. The broken lines and double headed arrows illustrate the parameters used for quantifying the EFS induced contractions $(A)$ and relaxations $(B)$.

immunoreactivity. All gall bladder neurones distinguished by PGP 9.5 immunoreactivity showed immunoreactivity for ChAT. Some gall bladder neurones colocalised immunoreactivity for both ChAT and NOS while others were immunonegative for NOS (fig 1).

Both smooth and varicose NOS immunoreactive nerve fibres were present within the three ganglionated plexuses, namely the muscular, serosal, and subepithelial plexuses. Nerve fibres which were NOS immunoreactive were also present within the non-ganglionated subepithelial plexus (fig 2A) and in close association with muscle (fig 2B). Within the ganglionated plexuses, NOS immunoreactive varicosities were often closely associated with nerve cells.

MORPHOLOGY AND NEUROCHEMICAL COMPOSITION OF NEURONES RETROGRADELY TRACED FROM MUSCLE

All neurones retrogradely traced from the muscle were unipolar with a few lamellar dendrites showing a typical Dogiel type I morphology (fig 3A, C). A few neurones were unipolar with numerous filamentous dendrites. NOS immunoreactivity was observed within both of these morphological types. Of the neurones retrogradely labelled from the gall bladder muscle, neurones with and without immunoreactivity for NOS were present within both the muscular and serosal plexuses (fig 3A-D).
NUMBERS AND DISTRIBUTION OF NEURONES RETROGRADELY TRACED FROM THE MUSCLE A total of 302 DiI labelled neurones were found within the muscular plexus (mean 30 (6.2); $78.0 \%$ of all labelled cells) and a total of 85 DiI labelled neurones observed within the serosal plexus (mean $11(2.1) ; 21.9 \%$ of all labelled cells) from five preparations. The epithelial plexus was devoid of labelled cells.

The labelled neurones were primarily located close to the application site $(100 \%$ located within $10 \mathrm{~mm}$ of the application site) (fig 4A, B). Of all DiI labelled neurones, 62 $(6.0) \%$ were NOS positive; a mean of 63 (7.1)\% NOS immunoreactive neurones within the muscular plexus and $61.7(10) \%$ within the serosal plexus. These NOS immunoreactive neurones showed a polarity in their distribution $(\mathrm{p}<0.01)$, with 24 (7.3) neurones of the muscular plexus projecting from the direction of the neck towards the apex of the gall bladder and 8.8 (2.6) neurones projecting from the apex towards the neck. Within the serosal plexus 12.3 (1.8) neurones projected towards the apex of the gall bladder with 2.7 (1.4) projecting towards the neck. The NOS negative DiI labelled neurones of the gall bladder were not polarised in their distribution. 
PHARMACOLOGICAL INVESTIGATIONS ON GALL BLADDER MOTILITY

In the presence of $0.1 \mu \mathrm{mol} / 1 \mathrm{CCK}-8$ alone, EFS produced consistent gall bladder contraction (control conditions; fig 5A). Under NANC conditions (fig 5B), the contractile response was reversed to relaxation $(p<0.03)$. This relaxation was abolished by L-NAME pretreatment $(p<0.005)$ (fig 5C). The affect of L-NAME was reversed by application of L-arginine. All EFS evoked responses were abolished by TTX. Cumulative data are presented in fig $5 \mathrm{D}$.

\section{Discussion}

During fasting, the gall bladder functions to store and concentrate bile released from the liver. During phase II of the migrating motor complex $^{19}$ or on chyme reaching the duodenum, the gall bladder discharges bile by contraction of its muscular wall. ${ }^{20}$ Contraction of the gall bladder is known to be primarily mediated by intrinsic cholinergic nerves acting via muscarinic receptors. ${ }^{16}$ Conversely, during the fasting state, hepatic bile enters the gall bladder via the cystic duct and this filling of the gall bladder is proposed as a passive process. $^{21}$ More recently, some evidence has emmerged supporting a role for NO in the filling of the gall bladder. ${ }^{15}$ Our study provides both anatomical and pharmacological evidence in the same species for intrinsic neurones of the gall bladder mediating excitatory and inhibitory neurotransmission to the muscle of the gall bladder by $\mathrm{ACh}$ and $\mathrm{NO}$, respectively.

Using immunohistochemical techniques, several neurochemicals have been demonstrated in the gall bladder of several mammalian species. ${ }^{9-11}$ All gall bladder neurones are reported to contain Ach. ${ }^{92}$ The present study showed localisation of ChAT within all possum gall bladder neurones, corroborating these previous findings. Our recent studies on the possum duodenum and colon have also demonstrated colocalisation in some motor neurones of both NOS and ChAT, markers of $\mathrm{NO}$ and ACh content.

Previous studies on innervation of circular muscle within the gastrointestinal tract have revealed only neurones with Dogiel type I morphology, the characteristic morphology of inter and/or motor neurones. ${ }^{1-5}$ This is reflected in the present study with only Dogiel type I neurones being found, with absence of type II neurones (the morphology characteristic of primary afferent neurones) among those retrogradely traced from the gall bladder muscle.

Demonstration of the marker for $\mathrm{ACh}$ within all gall bladder neurones together with some motor neurones without the marker for $\mathrm{NO}$ indicates significant motor innervation of the gall bladder by putative excitatory neurones. Functional studies have demonstrated an excitatory cholinergic input to the gall bladder musculature. ${ }^{16}$ Our data extend these previous findings, providing evidence for an intrinsic excitatory motor innervation of the gall bladder muscle, derived from the muscular and serosal plexuses.
We have shown that NOS immunoreactive neurones located within the muscular and serosal plexuses innervate the musculature of the gall bladder body. A similar innervation by NOS immunoreactive neurones of the sphincter of Oddi was recently demonstrated in the possum. ${ }^{23}$ Previous pharmacological data support our finding, showing a neurally mediated inhibition of the gall bladder musculature by NO. ${ }^{13}{ }^{14}$ This was initially demonstrated in vitro using human gall bladder muscle strips where TTX sensitive, EFS evoked relaxations were blocked by L-nitroarginine. ${ }^{13}$ More recent studies have demonstrated a similar mechanism in the guinea pig, ${ }^{24}$ sheep, ${ }^{14}$ and human ${ }^{25}$ gall bladder. Notably, these studies did not characterise the source of the inhibitory innervation. Our study provides the first neuroanatomical evidence for intrinsic inhibitory motor neurones in the gall bladder. We support these findings with pharmacological studies, optimised for detecting NO mediated neurotransmission and show relaxations mediated by neurally released NO within the gall bladder. Thus we provide evidence supporting the hypothesis for active relaxation of the gall bladder during filling.

Our study revealed a large number of neurones displaying immunoreactivity for NOS in the possum gall bladder unlike that reported in the guinea pig $^{8}$ or in humans. ${ }^{9} 10$ While no attempt was made to establish the proportion of NOS immunoreactive neurones within the entire population of gall bladder neurones, the presence of a dense plexus of NOS immunoreactive nerve fibres in the nonganglionated subepithelial plexus following organotypic tissue culture, as demonstrated in this study, suggests the presence of NOS in one or more classes of intrinsic gall bladder neurones other than motor neurones.

Interestingly, our study did not demonstrate any retrogradely traced nerve cells within the ganglionated subepithelial plexus on application of the tracer to the gall bladder muscle. Notably, our preliminary findings with tracer applied to the epithelial layer showed projection of nerve cells to the epithelium, exclusively from the ganglionated subepithelial plexus. ${ }^{26}$ Thus our data suggest that innervation and regulation of the gall bladder musculature is by neurones within the muscular and serosal plexuses, with preliminary data suggesting that control of epithelial function is by neurones located within the subepithelial plexus. The distribution of the putative inhibitory and excitatory neurones which project to the gall bladder body show a pattern of innervation which is unique to the gall bladder, differing significantly from the pattern of motor innervation present within the gastrointestinal tract. Most notably, the polarised innervation, proposed to underlie the ascending excitation and descending inhibition in the gastrointestinal tract, ${ }^{125}$ is absent in the gall bladder. This, and the polarity in the projection of the putative inhibitory neurones, is likely to underlie the unique motor behaviour of the gall bladder.

Immunoreactivity for ChAT is found in all gall bladder neurones in the possum, as shown 
previously in the guinea pig gall bladder. ${ }^{9}$ However, the intensity of this ChAT immunoreactivity varied considerably between neurones, including those within the same ganglion. Thus while all gall bladder neurones contain the enzyme required for ACh synthesis, the use of this excitatory transmitter may vary between these intrinsic neurones. Importantly, NOS immunoreactive neurones generally showed fainter immunoreactivity for ChAT than NOS negative neurones. This suggests that the primary transmitter in neurones which contain both transmitters may in fact be NO and are thereby primarily inhibitory in function. Importantly, our findings show that $\mathrm{NO}$ is involved in inhibitory transmission to the gall bladder musculature. The functional consequences of having low levels of ChAT within these putative inhibitory neurones awaits further pharmacological and physiological investigations.

In the human and guinea pig, vasoactive intestinal polypeptide (VIP) colocalises with NOS within gall bladder neurones. ${ }^{9}{ }^{10}$ Interestingly, increased innervation by NO and VIP containing nerves has been observed in some gall bladder disease states where motor abnormalities have also been shown. ${ }^{24} 27$ Our study defines the motor innervation by NOS containing intrinsic neurones showing that the majority of the innervation is comprised of putative inhibitory motor neurones. This suggests that altered innervation by NOS containing neurones would result in aberrant gall bladder motility. The possible localisation of VIP within motor neurones awaits further investigations. Importantly, to unravel the normal and aberrant functioning of the gall bladder, the mechanisms underlying its motor and secretory/absorptive activity need to be understood. This study extends our understanding of the motor innervation of the gall bladder, further elucidating the mechanisms which underlie gall bladder functions.

In summary, a large proportion of motor neurones innervating the muscle of the gall bladder body are putative inhibitory neurones, demonstrated by their immunoreactivity for NOS. The remaining proportion of gall bladder motor neurones are excitatory as they contain ChAT and are thus primarily cholinergic. These intrinsic neurones provide inhibitory and excitatory innervation of the gall bladder muscle, mediated by $\mathrm{NO}$ and $\mathrm{ACh}$, respectively. All gall bladder motor neurones project locally to the muscle from the muscular and serosal plexuses, with the majority of the innervation arising from the muscular plexus. There are no motor neurones present within the ganglionated subepithelial plexus. This study provides a combination of both anatomical and functional data characterising the intrinsic excitatory and inhibitory innervation of the gall bladder musculature.

Permission for the use of Australian Brush-tailed possums for this study was granted by the South Australian National Parks and Wildlife Services. This project was funded by a grant from the NH and MRC of Australia (No 102133), and the FMC Foundation.
1 Brookes SJ, Steele PA, Costa M. Identification and immunohistochemistry of cholinergic and non-cholinergic circular muscle motor neurons in the guinea-pig small intestine. Neuroscience 1991;42:863-78.

2 Porter AJ, Wattchow DA, Brookes SJ, et al. The neurochemical coding and projections of circular muscle motor neurons in the human colon. Gastroenterology 1997;113: 1916-23.

3 Brookes SJ, Hennig G, Schemann M. Identification of motor neurons to the circular muscle of the guinea pig gastric corpus. F Comp Neurol 1998;397:268-80.

4 Pfannkuche H, Reiche D, Firzlaff U, et al. Enkephalinimmunoreactive subpopulations in the myenteric plexus of the guinea-pig fundus project primarily to the muscle and not to the mucosa. Cell Tissue Res 1998;294:45-55.

5 Konomi H, Meedeniya ACB, Simula ME, et al. Characterization of duodenal circular muscle motor neurons in the Australian Brush-tailed possum. Gastroenterology 2000;118: A403.

6 Mawe GM, Gershon MD. Structure, afferent innervation, and transmitter content of ganglia of the guinea pig gallbladder: relationship to the enteric nervous system. $\mathscr{f}$ Comp Neurol 1989;283:374-90.

7 Padbury RT, Baker RA, Messenger JP, et al. Structure and innervation of the extrahepatic biliary system in the Australian possum, Trichosurus vulpecula. HPB Surg 1993; 7:125-39.

8 Mawe GM, Talmage EK, Cornbrooks EB, et al. Innervation of the gallbladder: structure, neurochemical coding, and physiological properties of guinea pig gallbladder ganglia. Microsc Res Tech 1997;39:1-13.

9 Talmage EK, Pouliot WA, Schemann M, et al. Structure and chemical coding of human, canine and opossum gallbladder ganglia. Cell Tissue Res 1996;284:289-302.

10 Uemura S, Pompolo S, Furness JB, et al. Nitric oxide synthase in neurons of the human gall-bladder and its colocalization with neuropeptides. $\mathcal{F}$ Gastroenterol Hepatol 1997; 12:257-65.

11 De Giorgio R, Zittel TT, Parodi JE, et al. Peptide immunoreactivities in the ganglionated plexuses and nerve fibers innervating the human gallbladder. F Auton Nerv Syst 1995;51:37-47.

12 Petersen KU, Goergen R, Hofken F, et al. Electrogenic bicarbonate secretion in gallbladder: induction by barium via neuronal, possibly VIP-ergic pathways. Naunyn Schmiedebergs Arch Pharmacol 1993;348:526-35.

13 McKirdy ML, McKirdy HC, Johnson CD. Non-adrenergic non-cholinergic inhibitory innervation shown by electrical field stimulation of isolated strips of human gall bladder muscle. Gut 1994;35:412-16.

14 Khoursheed M, Krajci D, Oriowo MA, et al. Neurogenic control of the ovine gallbladder: ultrastructural and functional study. Digestion 1998;59:335-42.

15 Greaves R, Miller J, O'Donnell L, et al. Effect of the nitric oxide donor, glyceryl trinitrate, on human gall bladder motility. Gut 1998;42:410-13.

16 Parkman HP, Pagano AP, Martin JS, et al. Electric field stimulation-induced guinea pig gallbladder contractions: role of calcium channels in acetylcholine release. Dig Dis Sci 1997;42:1919-25.

17 Meedeniya AC, Brookes SJ, Hennig GW, et al. The projections of 5-hydroxytryptamine-accumulating neurones in the myenteric plexus of the small intestine of the guinea-pig. Cell Tissue Res 1998;291:375-84.

18 Carbone A, Schloithe AC, Harvey JR, et al. Gastrinreleasing peptide stimulates possum gallbladder contractilreleasing peptide stimulates possum $\mathrm{g}$
ity in vitro. Peptides $1997 ; \mathbf{1 8}: 1067-71$.

19 Toouli J, Bushell M, Stevenson G, et al. Gallbladder emptying in man related to fasting duodenal migrating motor contractions. Aust N Z F Surg 1986;56:147-51.

20 Abiru H, Sarna SK, Condon RE. Contractile mechanisms of gallbladder filling and emptying in dogs. Gastroenterology 1994;106:1652-61.

21 Ryan JP. Motility of the gallbladder and biliary tree. In: Johnson LR, ed. Physiology of the gastrointestinal tract. New Johnson LR, ed. Physiology of the

22 Gonda T, Akiyoshi H, Ichihara K. Scanning electron microscopic observations of nerves in the guinea-pig gallbladder after an acetylcholinesterase histochemistry. F Smooth Muscle Res 1995;31:153-62.

23 Simula ME, Brookes SJH, Meedeniya ACB, et al. The distribution of nitric oxide synthase and vasoactive intestinal polypeptide immunoreactivity in the possum (Trichosurus Vulpecula) sphincter of Oddi and duodenum. Cell Tissue Res 2001;304:31-41.

24 Parkman HP, James AN, Bogar LJ, et al. Effect of acalculous cholecystitis on gallbladder neuromuscular transmission cholecystitis on gallbladder neuromuscular

25 Sanger PR, Sommerfeldt DW, Hanisch EW. Nonadrenergic, non-cholinergic regulation of stone-diseased and stone-free human gallbladders. Eur $\mathcal{f}$ Gastroenterol Hepatol 1999;11:1085-91.

26 Schloithe AC, Simula ME, Meedeniya ACB, et al. Projection and neurochemistry of neurones innervating the possum gallbladder mucosa. Int Hep Panc Bil Ass 2000;2:196.

27 Gonda T, Akiyoshi H, Ichihara K. Hyperplastic innervation of vasoactive intestinal peptide in human gallbladder with cholelithiasis. Histol Histopathol 1995;10:669-72. 